\title{
COVID-19, LONG COVID AND ITS NEUROLOGICAL EFFECTS
}

\section{ROY S ${ }^{*}$, CHOUDHURY L ${ }^{2}$ AND SARANGI $\mathbf{N}^{1}$}

1: Post-Graduate Department of Biotechnology, St. Xavier's College (Autonomous), 30, Mother Teresa Sarani, Kolkata - 700016, West Bengal, India

2: Department of Microbiology, Sarsuna College (under Calcutta University), 4/HB/A, Ho-ChiMinh Sarani, Sarsuna Upanagari, Kolkata - 700061, West Bengal, India

*Corresponding Author: Dr. Souvik Roy: E Mail: souvikroybiotech@sxccal.edu; Mob.: 9831316389

Received $15^{\text {th }}$ April 2021; Revised $16^{\text {th }}$ May 2021; Accepted $18^{\text {th }}$ June 2021; Available online $1^{\text {st }}$ March 2022 https://doi.org/10.31032/IJBPAS/2022/11.3.5936

ABSTRACT

The emergence of a novel strain of ß-coronavirus in Wuhan in early December 2019, signaled what were to be the most harrowing months for humanity in recent memory. Studies relating to the epidemiology and pathophysiology of the SARS-CoV-2 virus and its mutant variants, the causative pathogens for the COVID-19 pandemic and its second surge, revealed that the viral coat carried a spike protein specific to the angiotensin-converting enzyme 2 (ACE2)-receptors found on type II pneumocytes in the alveoli of human lungs. Victims of the pathogen primarily demonstrate pneumonia-like symptoms and a fatal cytokine storm, the combination of which leads to acute respiratory distress syndrome (ARDS) and systemic inflammatory response syndrome (SIRS). However, as the disease began to spread globally, a multitude of varied symptoms was brought to the fore, one of the most significant being neurological. With a rise in the prevalence of the long-term effects of the disease (Long COVID), it would be interesting to study the neurological changes which have either arisen or have continued onwards from the spark of initial infection. There are several reports of persistent neurological effects of the disease, ranging from mild symptoms including pain, sleep disorder, and all the way to the rare cases of GuillainBarre syndrome. This review aims to consolidate these severe aftermath related to COVID-19 and Long COVID, with special emphasis on the dilapidating neurological conditions.

Keywords: COVID-19, Long COVID, neurological effects, SARS-CoV-2 


\section{INTRODUCTION}

At the time of conception of this article, major portions of world population are still under the thrall of the virus. Despite valiant efforts at vaccination, some countries are observing their $4^{\text {th }}$ wave of the pandemic, while some, like ours, are just entering into their second. Till date, the SARS-CoV-2 virus has affected 154,188,318individuals and has taken the life of 3,227,163 humans. Even though the rate of recovery is high, and $131,602,640$ individuals have recovered as of now, it is quite apparent that the disease has several chronic effects [1, 2].

According to The Centers for Disease Control and Prevention (CDC), health issues which persist for longer than 4 weeks after an initial COVID-19 infection are described as 'post-COVID' conditions. One aspect of post-COVID Conditions is 'Long COVID', and it can affect any patient irrespective of whether they had severe or mild COVID-19 [3]. It has been observed to surface even months after the initial infection.

Some of the prominent symptoms of Long COVID include fatigue, brain fog, ageusia, anosmia, dizziness, heart palpitations, depression, anxiety and fever. Research has revealed that close to $87 \%$ of patients hospitalized with the disease has at least one symptom prevalent even 60 days post- discharge. These symptoms were usually noted to be fatigue and dyspnea, which have a trend to get worse after physical or mental activities [2]. Several studies have identified that one of the most prominent facets of Long COVID are the neurological manifestations. Prospective studies have revealed that close to $1 / 3^{\text {rd }}$ of patients hospitalized with the disease may develop long-term neurological complications. The complications observed include cognitive deficits, hyposmia as well as postural tremors. Patients cured of COVID-19 have also reported memory impairments and sleep disorders [4].

\section{Taxonomic Classification of SARS-CoV-2}

In the nomenclature of COVID-19, 'CO' stands for corona, 'VI' for virus and 'D' for the disease, which was first identified in December 2019. Earlier, the pathogen was referred to as '2019 novel coronavirus' ('2019-nCoV'). However, The International Committee on Taxonomy of Viruses (ICTV) renamed this virus as "Severe Acute Respiratory Syndrome Corona Virus 2 (SARS-CoV-2)" on $11^{\text {th }}$ February 2020 [5]. This is an enveloped, positive sense RNA virus, and belongs to the sub-family Coronavirinae under the family Coronaviridae in the order Nidovirales. It is 
at present the seventh member of the coronavirus family that infects humans. It has been classified under the Orthocoronaviridae subfamily, and belongsto a clade under the subgenus Sarbecovirus [6, 7].

\section{Epidemiology of COVID-19}

Epidemiologically, the COVID-19 outbreak originated in Wuhan, the capital city of Hubei Province in the People's Republic of China [6]. The World Health Organization (WHO) report indicates that the virus most possibly originated in November 2019, but was not in wide circulation before the third week of 2020. Speculative studies have identified the Wuhan South China Wholesale Sea Food Market as the origin of the epidemic, and since then, a number of environmental samples from around the live animal section of the market were found to be positive for SARS-CoV-2 [6]. However, whether the strain itself originated from the market is still debatable, and under the scanner. But the market definitely played a defining role as a cluster for the spread of the disease [8].

Among coronaviruses analysed phylogenetically, the closest relative to SARSCoV-2 virus inhabits horseshoe bats (Rhinolophus spp.) and pangolins. However, there is no conclusive proof to implicate them as the origin or the intermediate medium for transmission of the virus [8].

The conclusive statement for the WHO report was that the virus was most likely introduced to the human population through an intermediate host.

\section{Generalized symptoms of COVID-19}

The primary manifestations of COVID-19 infection, with the virus targeting the respiratory system, are severe pneumonia (with CT-SCAN revealing the presence of ground-glass opacity nodules and woolly patches in the lungs), detectable serum SARS-CoV-2 viral load (RNAaemia), acute respiratory distress syndrome (ARDS) and systemic inflammatory response syndrome (SIRS). Along with these symptoms, various dermatological, neurological and gastrointestinal manifestations are also reported, with one of the most worrying aspect that the disease seems to have is on the human brain. High blood levels of cytokines and chemokines predominate in patients with COVID-19 infections. This 'cytokine storm' includes IL1- $\beta$, IL1RA, IL7, IL8, IL9, IL10, basic FGF2, G-CSF, GM-CSF, IFN $\gamma$, IP10, MCP1, MIP1 $\alpha$, MIP1 $\beta$, PDGFB, TNF $\alpha$ and VEGFA. Critically ill patients who were admitted to the intensive care units (ICUs) of hospitals usually display high levels of proinflammatory cytokines like IL2, IL7, IL10, 
GCSF, IP10, MCP1, MIP1 $\alpha$, and TNF $\alpha$. These were shown to promote disease severity [9-13]. All these together are believed to play a part in the disease symphony, complementing the more severe effects of the disease, including death [9-13].

\section{Pathogenesis of SARS-COV-2 virus}

The spike protein of SARS-COV-2 has a receptor binding domain which is complementary to the angiotensin-converting enzyme 2 (ACE2)-receptor found primarily on the membrane of type II pneumocytes of the lung alveoli [14]. Due to receptor compatibility and certain novel mutations in the receptor binding domain, the SARSCoV-2 virus has a heightened affinity for binding to these receptors [15].

Following membrane fusion, the viral genome is released into the cytoplasm, after which, in presence of host RNA dependent RNA-polymerase, multiple copies of the positive sense viral RNA are formed. At the same time, host ribosomes translate the mRNA forming various viral polyproteins. These polyproteins, in presence of various proteases, are cleaved into functional proteins. Following this, the viral genetic material, along with the functional proteins produced, is packaged into new virion particles. Due to a gradual increase in the intracellular concentration of active virion particles, the host cells are lysed, releasing the viral load $[9,11,15]$.

The cell death releases inflammatory mediators such as IL6, TNF- $\alpha$ and IL1. Apart from acting as chemokines for signaling the action of alveolar macrophages, these chemicals vasodilate the alveolar capillaries that causes plasma to leak out into the alveolar surroundings. The increased interstitial fluid content builds pressure on the alveolar walls, until it is enough to penetrate the walls of the alveolus. This will flood the alveolus, causing alveolar edema $[16,17]$. The primary function of the type II pneumocyte cells is to produce surfactant. Due to viral lysis, they cannot do so anymore. Residual surfactant is drowned out due to alveolar oedema. This increases the surface tension and by Laplace's law, increases the collapsing pressure of the alveolus.

The inflammatory molecules released by the alveolar macrophages will also attract neutrophils into the alveolus. The release of reactive oxygen species (ROS) and proteases by the neutrophils to destroy the viruses also destroys virus-infected cells, impairing gaseous exchanges. As the cells die, they will collect inside the collapsing alveolus, seeding the formation of consolidations. The macrophages, neutrophils, secreted proteins 
and viral particles will all start accumulating within the alveolus, leading to consolidation and productive cough. The alveoli will finally give up, leading to hypoxia, increased work of breathing, resulting in ARDS. Impediment in proper gas exchange will decrease blood pO2, stimulating peripheral chemoreceptors to increase the heart beat. This will result in tachycardia and increased rates of respiration [17-19].

Presence of IL-6 and IL-1 in blood, and in the hypothalamus will induce fever. Increased IL concentrations will increase membrane permeability of circulatory vessels. The plasma will leak out, decreasing blood volume. Total peripheral resistance will also decrease with the decreasing blood volume, leading to hypotension. This can, therefore decrease perfusion and cause multisystem dysfunction event [16-19].

\section{SARS-CoV-2 INFECTIONS OF THE HUMAN NERVOUS SYSTEM}

As the pandemic has progressed, two of the most disturbing symptoms that have surfaced are the neurological and neuropsychiatric effects of the disease.

\section{Sites of infection in the human nervous} system

It is well established that coronaviruses $(\mathrm{CoV})$ possess the capability to infect the human nervous system. A similar predisposition is also observed in cases of both Middle East Respiratory Syndrome (MERS) and Severe Acute Respiratory Syndrome (SARS) epidemics. Double immunofluorescence studies employing fluorescent-tagged antibodies to virus and host cell surface markers have shown infection of fetal astrocytes, and of adult microglia and adult astrocytes by strain OC43 strain of the human CoV [20]. SARSCoV-2 virus is no exception. The viral RNA has been successfully identified and isolated from the cerebrospinal fluid (CSF) [21, 22]. This establishes the virus as possessing neuroinvasive properties, with the capability to infect the human central nervous system (CNS) including brain, and peripheral nervous system (PNS) through post-infection immune-mediated pathways, and in situ infection of the CNS, along with viral hyperinflammatory and hypercoagulable states. CNS-associated symptoms include encephalitis, ischemic stroke, meningitis and headache, among several other prominent ones. Also Guillain-Barre Syndrome, muscle injury and other PNS-associated symptoms are found to surface. Different kinds of nonneuronal cells in the olfactory epithelium, along with the epithelial cells of the cerebral vasculature, express ACE2 receptor and this may act as a facilitator for the multiplication, 
growth and entry point of the SARS-CoV-2 virus $[\mathbf{2 0}, \mathbf{2 3}]$. It has been suggested that the virus may enter the CNS through the vasculature, nerve structure, CSF or the lymphatic systems [24-26]. The presence of various types of non-neuronal cells in the olfactory epithelium, as well as on the epithelial cells of the cerebral vasculature which express ACE2 receptor may act as a facilitator for the multiplication, accumulation and entry point of the SARSCoV-2 virus $[20,23]$. It may be so that the virus can enter transneuronally via the olfactory nerve, approaching the brain across the cribriform plate [27]. It is highly probable that the pathophysiological reason behind the loss of smell, as reported by various patients, is a direct result of the effect of the virus on the 'nose-to-brain' route [28, 29]. Since 'nose-to-brain' route is used for medicine delivery, this pathway could very well act as the pathway for brain infection by the virus [28, 29]. Post-mortem (PM) studies have presented evidence that the virus is present in the neural and capillary endothelial cells of the brain's frontal lobe [30]. It also seems that co-morbidities like diabetes and hypertension enhances the expression of ACE2 in the brain and promotes neurotropism. The circulation of the viral particles in the blood stream, leading to their interaction with the capillary endothelium and subsequent destruction, could provide a basis for the access of the viral particles to the brain. This may be a cause for brain hemorrhage long before the lethal effects of the neuronal damage manifest. One of the primary manifestations of the disease is ARDS-related hypoxic conditions, and it may so happen that the condition of the patient worsens due to infection of the pneumotaxic center in the brainstem following the viral invasion $[31,32]$.

\section{Direct effects of COVID-19 on the Human Brain}

The major neurological symptoms of COVID-19 include headache, myalgia and malaise among the major neurological symptoms. The effect is comprehensive, and accounts for infection throughout the neural axis as well as the cerebral vasculature. The major complications implicated in this disease include meningitis, encephalopathy, meningoencephalitis, ischemic stroke, acute necrotizing encephalitis and Guillain-Barre Syndrome [27].

Indirect effects of COVID-19 on the Human Brain

Chances of cerebral vasculature complications is enhanced through the dysregulation of blood pressure as a result of downregulation of the ACE2 receptors as a 
result of the disease [33]. The development of SIRS is a prevalent syndrome linked to viral infections like COVID-19. The oxidative stress resulting from the acute inflammation-mediated early release of proinflammatory cytokines may sometimes not be compensated by the antioxidants in the system. This may increase the systemic oxidative stress, as a result of which, the brain would be in a susceptible position since it is a metabolizer of oxygen and has no antioxidant mechanism [34].

It has been established that the brain-lungbrain axis is interconnected, and neurological dysfunction along with injury may be related to acute respiratory distress [35].

SARS-CoV-2 elicits a potent cytokine storm, and resultant apoptosis and cell death arising from a marked inflammatory and immune response. COVID-19 patients have elevated levels of IL-1 $\beta$, IFN- $\gamma$, IP-10, MCP-1, IL-4 and IL-10 $[9,11,12]$. The excitation of the immune system results in vascular hyperpermeability, along with coagulopathies, associated neural degeneration and multiorgan failure [36]. Inflammatory damage to the Blood Brain Barrier (BBB) has been observed to be the reason behind various neurodegenerative and CNS infections. The presence of elevated levels of proinflammatory cytokines such as TNF- $\alpha$ and
IL-6 is strongly correlated with neuroinflammatory signaling [37].

There is a potent disbalance in the redox state of general body physiology, which may enhance tissue damage along with neuronal degeneration [38-40]. The hypoxic conditions resulting from alveolar infection and impaired gas exchange raises the anaerobic metabolism rate in the mitochondria of the brain cells $[\mathbf{4 1}, \mathbf{4 2}]$. This may result in the promotion of vasodilation along with swelling of the blood cells, interstitial edema, cerebral blood flow obstruction, ischemia and congestion [43].

Additionally, there are also associated gastrointestinal tract symptoms with urinary blood control dysregulation.

\section{NEUROLOGICAL EFFECTS OF LONG COVID}

The concept of Long COVID is slowly taking form, and countries are moving forward to tackle this resilient disease. A recent study established that nearly $87.4 \%$ of patients who had recovered from COVID-19 still reported at least one disease symptom, mostly fatigue or dyspnea [2]. An important aspect of Long COVID lies in the neurological manifestations of the disease. This may range from mild symptoms such as headache, hyposmia, hypogeusia and fatigue to more severe complications involving pain, 
cognitive impairment and Guillain-Barre syndrome.

In a seminal study carried out between $16^{\text {th }}$ June 2020 and $3^{\text {rd }}$ September 2020, 76\% of the patients with confirmed COVID-19 who had been discharged from the Jin Yin-tan Hospital, Wuhan, China between $7^{\text {th }}$ January 2020 and $29^{\text {th }}$ May 2020, were reported as having neurological discomforts. Complaints recorded six months after the onset of symptoms included fatigue, muscle weakness, sleep difficulties, anxiety and depression [44].

Pre-COVID 19 literature illuminates the fact that one-third of patients with ICU stays resulting from acute respiratory failure demonstrate high degrees of cognitive impairment. This was found to be comparable to patients suffering from moderate brain injury [45]. Long COVID ICU stays are similar, as has been confirmed from studies carried out in Britain, Canada and Finland. Due to the infectious nature of the disease, the restrictions imposed on either patient-patient party interaction and patienthealthcare worker interaction might play a dominant role in such reduced cognitive stimulations. Post-operative or post-treatment rehabilitation is reduced or abandoned due to the disease, upending efforts to prevent the neurological complications [46].
Some direct effects of Long COVID may also be a result of encephalitis, stroke or exposure to hypoxic conditions. However, it is interesting to note the impact of the disease on patients who have recovered from COVID-19. In a study carried out on 29 subjects, it was revealed that there was a stark impairment in sustained attention in patients who had recovered from COVID-19 [47]. The same study identified a plausible link between this effect and the inflammatory response to COVID-19.

The acute phase of the disease was followed by inability to return to daily routines with exhibition of different symptoms [48]. Ischemic stroke or silent stroke resulting from COVID-19 leads to drop in oxygen concentration in the brain, resulting in damage. Silent strokes can impact sections of the brain related to coordination, resulting in impairment of attention spans [49]. Since the virus has prominent neurotropic properties, it may also increase a person's risk towards Alzheimer's and Parkinson's diseases. Disease progression may be exacerbated through increased oxidative stress, followed by impairment of glutamatergic signaling, cerebrovascular accidents, heightened cytokine response, direct effect interaction of the viral particles with neuronal function and glial activity compound factors which 
influence neuropsychiatric disorders. These neuropsychiatric and cognitive disabilities would result in debilitating occupational and functional hazards which might directly lead to cognitive dysfunction, with higher levels of Post-Traumatic Stress Disorder (PTSD) and depressive symptoms [48]. The virus is specific for the ACE2 cells expressed in nonneuronal cells and may engage in further deterioration of the vascular architecture through hypoperfusion as a result of demyelination, neurodegeneration and cellular senescence. As a result, the energy substrate required for maintenance of the neuronal networks might disappear, resulting in the accelerated cognitive decline in the elderly. There remain possibilities of retrograde and anterograde amnesia because of damage to the limbic and cortical regions [48]. Brain fog, dizziness and fatigue have also been reported [50].

\section{CONCLUSION}

It has been well over a year since the pandemic began. Cutting edge science has progressed in leaps and bounds to formulate vaccination strategies as well as execute the same. There are robust medical treatment protocols, triage methods and testing centers. Recovery rates are in general high. That is when we have to ask the question, what are we qualifying as "recovered". It is now apparent across peer-reviewed wellestablished studies that chronic COVID-19, or the long haulers are facing dire threats to life and livelihood with various debilitating symptoms. A vast percentage of such symptoms are neurological in nature, with neuropsychiatric disability and high prospective of cascading Alzheimer's or Parkinson's Diseases. The pathophysiology of Long COVID requires minute examination of molecular pathways, statistical evaluation of broad-based clinical studies followed by robust schemes for post-COVID rehabilitation programs. As ever we fight against the acute conditions of this disease, we need to identify with COVID-19 as a chronic disease as well. At the fore of these are the neurological manifestations, which are ever increasing, necessitating further investigation and studies to be performed to deal with this hidden onslaught.

\section{ACKNOWLEDGEMENTS}

The authors express their deepest gratitude to Rev. Dr. Dominic Savio, S.J., Principal and Rector, St. Xavier's College (Autonomous), Kolkata and Dr. Subhankar Tripathi, Principal, Sarsuna College, Kolkata.

\section{REFERENCES}

[1] COVID-19 Map - Johns Hopkins Coronavirus Resource Center n.d. 
https://coronavirus.jhu.edu/map.html

(accessed October 16, 2020).

[2] Carfì A, Bernabei R, Landi F, Gemelli Against COVID-19 PostAcute Care Study Group. Persistent Symptoms in Patients After Acute COVID-19. JAMA 2020; 324: 603-5. https://doi.org/10.1001/jama.2020.12 603.

[3] CDC. COVID-19 and Your Health. Centers for Disease Control and Prevention 2020. https://www.cdc.gov/coronavirus/201 9-ncov/long-term-effects.html (accessed April 17, 2021).

[4] Long-Term Neurologic Symptoms Emerge in COVID-19 2021. https://www.medpagetoday.com/infec tiousdisease/covid19/90587 (accessed April 13, 2021).

[5] Naming the coronavirus disease (COVID-19) and the virus that causes it n.d.

https://www.who.int/emergencies/dis eases/novel-coronavirus2019/technical-guidance/naming-thecoronavirus-disease-(covid-2019)and-the-virus-that-causes-it (accessed October 22, 2020).

[6] Zhu N, Zhang D, Wang W, Li X, Yang B, Song J, et al. A Novel
Coronavirus from Patients with Pneumonia in China, 2019. New England Journal of Medicine 2020; 382: 727-33.

https://doi.org/10.1056/NEJMoa2001 017.

[7] Yin Y, Wunderink RG. MERS, SARS and other coronaviruses as causes of pneumonia. Respirology (Carlton, Vic) 2018; 23: 130-7. https://doi.org/10.1111/resp.13196.

[8] Virus origin / Origins of the SARSCoV-2 virus n.d. https://www.who.int/healthtopics/coronavirus/origins-of-thevirus (accessed April 17, 2021).

[9] Huang C, Wang Y, Li X, Ren L, Zhao J, Hu Y, et al. Clinical features of patients infected with 2019 novel coronavirus in Wuhan, China. Lancet 2020; 395: 497-506.

https://doi.org/10.1016/S01406736(20)30183-5.

[10] Chen N, Zhou M, Dong X, Qu J, Gong $\mathrm{F}$, Han $\mathrm{Y}$, et al. Epidemiological and clinical characteristics of 99 cases of 2019 novel coronavirus pneumonia in Wuhan, China: a descriptive study. Lancet 2020; 395: 507-13. 
https://doi.org/10.1016/S0140-

6736(20)30211-7.

[11] Huang X, Wei F, Hu L, Wen L, Chen K. Epidemiology and Clinical Characteristics of COVID-19. Arch Iran Med 2020; 23: 268-71. https://doi.org/10.34172/aim.2020.0 9.

[12] Channappanavar R, Perlman S. Pathogenic human coronavirus infections: causes and consequences of cytokine storm and immunopathology. Semin Immunopathol., 2017; 39: 529-39. https://doi.org/10.1007/s00281-0170629-x.

[13] McGonagle D, Sharif K, O’Regan A, Bridgewood C. The Role of Cytokines including Interleukin-6 in COVID-19 induced Pneumonia and Macrophage Activation SyndromeLike Disease. Autoimmun Rev 2020; 192537. https://doi.org/10.1016/j.autrev.2020 .102537 .

[14] Zhou P, Yang X-L, Wang X-G, Hu $\mathrm{B}$, Zhang $\mathrm{L}$, Zhang $\mathrm{W}$, et al. A pneumonia outbreak associated with a new coronavirus of probable bat origin. Nature 2020; 579: 270-3. https://doi.org/10.1038/s41586-0202012-7.

[15] Xia S, Zhu Y, Liu M, Lan Q, Xu W, $\mathrm{Wu} \mathrm{Y}$, et al. Fusion mechanism of 2019-nCoV and fusion inhibitors targeting HR1 domain in spike protein. Cellular \& Molecular Immunology 2020; 17: 765-7. https://doi.org/10.1038/s41423-0200374-2.

[16] Cascella M, Rajnik M, Cuomo A, Dulebohn SC, Di Napoli R. Features, evaluation and treatment coronavirus (COVID-19). Statpearls [Internet] 2020.

[17] $\mathrm{Xu} \mathrm{Z,} \mathrm{Shi} \mathrm{L,} \mathrm{Wang} \mathrm{Y,} \mathrm{Zhang} \mathrm{J,}$ Huang L, Zhang C, et al. Pathological findings of COVID-19 associated with acute respiratory distress syndrome. The Lancet Respiratory Medicine, 2020; 8: 4202. https://doi.org/10.1016/S22132600(20)30076-X.

[18] Wu Z, McGoogan JM. Characteristics of and Important Lessons From the Coronavirus Disease 2019 (COVID-19) Outbreak in China: Summary of a Report of 72314 Cases From the Chinese Center for Disease Control and Prevention. JAMA 2020; 323: 1239. 
https://doi.org/10.1001/jama.2020.2 648.

[19] Mason RJ. Pathogenesis of COVID19 from a cell biology perspective. European Respiratory Journal 2020;55.

https://doi.org/10.1183/13993003.00 607-2020.

[20] Bonavia A, Arbour N, Yong VW, Talbot PJ. Infection of primary cultures of human neural cells by human coronaviruses 229E and OC43. J Virol., 1997; 71: 800-6.

[21] Arbour N, Day R, Newcombe J, Talbot PJ. Neuroinvasion by Human Respiratory Coronaviruses. J. Virol., 2000; 74: 8913-21.

[22] Saiegh FA, Ghosh R, Leibold A, Avery MB, Schmidt RF, Theofanis $\mathrm{T}$, et al. Status of SARS-CoV-2 in cerebrospinal fluid of patients with COVID-19 and stroke. J Neurol Neurosurg Psychiatry 2020; 91: 846-8. https://doi.org/10.1136/jnnp2020-323522.

[23] Li M-Y, Li L, Zhang Y, Wang X-S. Expression of the SARS-CoV-2 cell receptor gene ACE2 in a wide variety of human tissues. Infectious Diseases of Poverty 2020; 9: 45. https://doi.org/10.1186/s40249-02000662-x.

[24] Desforges M, Le Coupanec A, Dubeau P, Bourgouin A, Lajoie L, Dubé M, et al. Human Coronaviruses and Other Respiratory Viruses: Underestimated Opportunistic Pathogens of the Central Nervous System? Viruses 2019; 12. https://doi.org/10.3390/v12010014.

[25] Gu J, Gong E, Zhang B, Zheng J, Gao Z, Zhong Y, et al. Multiple organ infection and the pathogenesis of SARS. J Exp Med 2005;202:41524.

https://doi.org/10.1084/jem.2005082 8.

[26] Xu J, Zhong S, Liu J, Li L, Li Y, $\mathrm{Wu} \mathrm{X}$, et al. Detection of Severe Acute Respiratory Syndrome Coronavirus in the Brain: Potential Role of the Chemokine Mig in Pathogenesis. Clin Infect Dis 2005;41:1089-96. https://doi.org/10.1086/444461.

[27] Natoli S, Oliveira V, Calabresi P, Maia LF, Pisani A. Does SARSCov-2 invade the brain? Translational lessons from animal 
models. Eur J Neurol 2020. https://doi.org/10.1111/ene.14277.

[28] Butowt R, Bilinska K. SARS-CoV2: Olfaction, Brain Infection, and the Urgent Need for Clinical Samples Allowing Earlier Virus Detection. ACS Chem Neurosci 2020.

https://doi.org/10.1021/acschemneur o.0c00172.

[29] Picone P, Sabatino MA, Ditta LA, Amato A, San Biagio PL, Mulè F, et $a l$. Nose-to-brain delivery of insulin enhanced by a nanogel carrier. J Control Release 2018; 270: 23-36. https://doi.org/10.1016/j.jconrel.201 7.11.040.

[30] Paniz-Mondolfi A, Bryce C, Grimes Z, Gordon RE, Reidy J, Lednicky J, et al. Central nervous system involvement by severe acute respiratory syndrome coronavirus- 2 (SARS-CoV-2). Journal of Medical Virology 2020; 92: 699-702. https://doi.org/10.1002/jmv.25915.

[31] Li Y, Bai W, Hashikawa T. The neuroinvasive potential of SARS-CoV2 may play a role in the respiratory failure of COVID-19 patients. J Med Virol 2020. https://doi.org/10.1002/jmv.25728.
[32] Nuzzo D, Picone P. Potential neurological effects of severe COVID-19 infection. Neurosci Res 2020; 158: 1-5.

https://doi.org/10.1016/j.neures.202

0.06.009.

[33] Garg RK. Spectrum of Neurological Manifestations in Covid-19: A Review. Neurology India 2020; 68: 560. https://doi.org/10.4103/00283886.289000 .

[34] Biswas SK. Does the Interdependence between Oxidative Stress and Inflammation Explain the Antioxidant Paradox? Oxid Med Cell Longev 2016; 2016. https://doi.org/10.1155/2016/569893 1.

[35] Stevens RD, Puybasset L. The brain-lung-brain axis. Intensive Care Med 2011; 37: 1054-6. https://doi.org/10.1007/s00134-0112233-1.

[36] Tay MZ, Poh CM, Rénia L, MacAry PA, Ng LFP. The trinity of COVID19: immunity, inflammation and intervention. Nat Rev Immunol 2020: 1-12. https://doi.org/10.1038/s41577-0200311-8. 
[37] Rochfort KD, Cummins PM. The blood-brain barrier endothelium: a target for pro-inflammatory cytokines. Biochem Soc Trans 2015; 43: 702-6.

https://doi.org/10.1042/BST201403 19.

[38] Martínez Leo EE, Segura Campos MR. Systemic Oxidative Stress: A key Point in Neurodegeneration - A Review. J Nutr Health Aging 2019; 23: 694-9.

https://doi.org/10.1007/s12603-0191240-8.

[39] Nuzzo D, Picone P, Caruana L, Vasto S, Barera A, Caruso C, et al. Inflammatory mediators as biomarkers in brain disorders. Inflammation 2014; 37: 639-48. https://doi.org/10.1007/s10753-0139780-2.

[40] Cevenini E, Caruso C, Candore G, Capri M, Nuzzo D, Duro G, et al. Age-related inflammation: the contribution of different organs, tissues and systems. How to face it for therapeutic approaches. Curr Pharm Des 2010; 16: 609-18. https://doi.org/10.2174/1381612107 90883840 .
[41] Di Carlo M, Giacomazza D, Picone P, Nuzzo D, San Biagio PL. Are oxidative stress and mitochondrial dysfunction the key players in the neurodegenerative diseases? Free Radic Res 2012; 46: 1327-38. https://doi.org/10.3109/10715762.20 12.714466 .

[42] Abdennour L, Zeghal C, Dème M, Puybasset L. [Interaction brainlungs]. Ann Fr AnesthReanim 2012; 31: e101-107. https://doi.org/10.1016/j.annfar.201 2.04.013.

[43] Guo Y-R, Cao Q-D, Hong Z-S, Tan Y-Y, Chen S-D, Jin H-J, et al. The origin, transmission and clinical therapies on coronavirus disease 2019 (COVID-19) outbreak - an update on the status. Mil Med Res $2020 ; 7: 11$.

https://doi.org/10.1186/s40779-02000240-0.

[44] Huang C, Huang L, Wang Y, Li X, Ren L, Gu X, et al. 6-month consequences of COVID-19 in patients discharged from hospital: a cohort study. The Lancet 2021; 397: 220-32.

https://doi.org/10.1016/S01406736(20)32656-8. 
[45] Pandharipande PP, Girard TD, Jackson JC, Morandi A, Thompson $\mathrm{JL}$, Pun BT, et al. Long-Term Cognitive Impairment after Critical Illness. New England Journal of Medicine 2013; 369: 1306-16. https://doi.org/10.1056/NEJMoa130 1372.

[46] Hosey MM, Needham DM. Survivorship after COVID-19 ICU stay. Nat Rev Dis Primers 2020; 6: 60. https://doi.org/10.1038/s41572020-0201-1.

[47] Zhou H, Lu S, Chen J, Wei N, Wang D, Lyu H, et al. The landscape of cognitive function in recovered COVID-19 patients. Journal of Psychiatric Research 2020; 129: 98-102.

https://doi.org/10.1016/j.jpsychires. 2020.06.022.

[48] The chronic neuropsychiatric sequelae of COVID-19: The need for a prospective study of viral impact on brain functioning Erausquin - - Alzheimer's \&amp; Dementia - Wiley Online Library n.d. https://alzjournals.onlinelibrary.wile y.com/doi/10.1002/alz.12255 (accessed April 16, 2021).
[49] Smith EE, Saposnik G, Biessels GJ, Doubal FN, Fornage M, Gorelick $\mathrm{PB}$, et al. Prevention of Stroke in Patients With Silent Cerebrovascular Disease: A Scientific Statement for Healthcare Professionals From the American Heart Association/American Stroke Association. Stroke 2017; 48: e4471.

https://doi.org/10.1161/STR.000000 0000000116.

[50] Baig AM. Deleterious Outcomes in Long-Hauler COVID-19: The Effects of SARS-CoV-2 on the CNS in Chronic COVID Syndrome. ACS Chem Neurosci., 2020; 11: 401720.

https://doi.org/10.1021/acschemneur o.0c00725. 